\title{
Spectrophotometric assessment of bowel perfusion during low anterior resection: a prospective study
}

\author{
Ibrahim Darwich $^{1}\left[\right.$ [D $\cdot$ Darmadi Rustanto $^{1} \cdot$ Ronald Friedberg $^{1} \cdot$ Frank Willeke $^{1}$
}

Received: 10 April 2019 / Accepted: 25 September 2019 / Published online: 12 October 2019

(c) The Author(s) 2019

\begin{abstract}
Good perfusion of the bowel and a tension-free anastomosis are the two main prerequisites for an uneventful anastomotic healing in rectal surgery. This prospective cohort study investigates the noninvasive intraoperative spectrophotometric assessment of the bowel perfusion using a device called "Oxygen to See" $\left(\mathrm{O} 2 \mathrm{C}^{\circledR}\right)$. Forty patients, planned for low anterior resection, were prospectively enrolled in this study to undergo an intraoperative spectrophotometric assessment of the bowel. Three different $\mathrm{O}_{2} \mathrm{C}^{\circledR}$ parameters were collected from the colonic and the rectal stumps before fashioning the anastomosis: $\mathrm{SO} 2$ (capillary venous oxygen saturation), $\mathrm{rHb}$ (relative hemoglobin amount), and flow (blood flow velocity). Bowel perfusion was also assessed with the cold-steel-test (CST), which involves severing the colic marginal artery of Drummond at the tip of the colon stump. The data collected from the spectrophotometric measurement and the CST were analyzed for correlation of both methods with respect to each other and to the outcome of the anastomosis. Nine patients were excluded due to different reasons, thus leaving 31 patients for statistical analysis. Three flow parameters collected at the colonic stump significantly predicted an anastomotic leak ( $p: 0.0057 ; p: 0.0250 ; p: 0.0404)$. One rHb parameter collected at the rectal stump correlated weakly with the anastomotic outcome ( $p: 0.0768)$. The CST did not correlate significantly with anastomotic leak ( $p$ : 0.1195), but showed significant correlations to some rHb values. Intraoperative noninvasive spectrophotometric measurement is feasible and could be a useful method in assessing bowel perfusion before fashioning a colorectal anastomosis.
\end{abstract}

Keywords Bowel perfusion $\cdot$ Low anterior resection $\cdot{\mathrm{O} 2 \mathrm{C}^{\circledR}}^{\circledR}$ Colic marginal artery $\cdot$ Anastomotic leak $\cdot$ Cold steel test

$\begin{array}{ll}\text { Abbreviations } \\ \text { AL } & \text { Anastomotic leakage } \\ \text { AUC } & \text { Area under the curve } \\ \text { CST } & \text { Cold steel test } \\ \text { HT } & \text { High tie } \\ \text { ICG } & \text { Indocyanin green } \\ \text { IMA } & \text { Inferior mesenteric artery } \\ \text { KI } & \text { Karnofsky index } \\ \text { LAR } & \text { Low anterior resection } \\ \text { MBP } & \text { Mechanical bowel preparation } \\ \text { MDT } & \text { Multidisciplinary team } \\ \text { nCRT } & \text { Neoadjuvant chemoradiotherapy } \\ \text { nRT } & \text { Neoadjuvant radiotherapy }\end{array}$

Ibrahim Darwich

Ibrahim@darwich.net

1 Department of Surgery, St. Marienkrankenhaus Siegen, Kampenstr. 51, 57072 Siegen, Germany

\section{Introduction}

A symptomatic anastomotic leak (AL) after a low anterior resection (LAR) for rectal cancer is one of the most distressing and feared complications, associated with a high level of morbidity and a leak-related mortality rate of as high as 39\% [1-4]. A low rectal anastomosis, neoadjuvant radiation therapy, intraoperative complications, and the male sex have been implicated as independent risk factors for anastomotic leaks [5, 6]. A defunctioning loop ileostomy has been shown to significantly reduce the risk of AL [7]. Yet, while taking those risks into consideration, the surgeon must ensure that the anastomosis is fashioned tension-free and under adequate blood supply to the bowel ends [8].

A high tie (HT) technique, which involves central division of the inferior mesenteric artery (IMA) to achieve maximal bowel length in an LAR [9], has been advocated by many authors $[10,11]$. Yet, while other studies suggested that division of the IMA below the origin of the left colic artery (low tie) is preferable in terms of bowel blood supply [12], there 
is still no clear clinical evidence that favors one technique over the other [13].

Judging blood supply according to the outer appearance of the bowel has been shown to be inadequate for assessing perfusion [14]. As an alternative to assess bowel perfusion, the cold-steel-test (CST) has been described. This involves severing the colic marginal artery of Drummond right at the end of the stump of the descending colon using the scissors and observing the resulting pulsatile jet of blood [15-17].

No other methods played a serious role in evaluating bowel perfusion in colorectal surgery before this study was initiated in 2015.

In this work, we evaluated the intraoperative spectrophotometric assessment of bowel perfusion using a device called “Oxygen to See” $\left(\mathrm{O} 2 \mathrm{C}^{\circledR}\right.$, LEA-Medizintechnik, Giessen, Germany). This device utilizes laser Doppler flowmetry and tissue spectrometry to quantitatively assess tissue perfusion. There is experimental and clinical evidence supporting the reproducibility of measurements of this device [18-21]. There have also been clinical studies describing the use of this device in colorectal surgery. In one study, it was utilized to show a decrease of bowel perfusion after mobilization of the bowel und dividing the mesentery [22]. In another study, it was used to compare the difference in bowel perfusion after performing an HT and a low tie (LT) technique [23]. In both studies, however, the assumption was made that this device was adequate, if not also legitimate, for performing the task of assessing bowel perfusion, yet without supporting evidence. No attempt was made in those studies to define cut-off values of measurements.

We attempted in this study to evaluate the feasibility of intraoperative use of this device and check for its validity by analyzing the correlation of the parameters measured with the CST. Furthermore, we tried to find a correlation between the measured parameters and anastomotic leak.

\section{Methods}

Forty patients, planned for elective laparoscopic or open low anterior resection for rectal cancer, were eligible to be enrolled in this prospective study if they were above 18 years of age and had a Karnofsky index (KI) of $70 \%$ or higher. Written informed consent was obtained from all patients. The ethics committee of the Mannheim medical university granted approval for the study protocol (2015-410 M-MA§23b MPG).

Patients underwent neoadjuvant long-course chemoradiation (nCRT) or short-course radiation therapy alone (nRT) if indicated by our multidisciplinary team (MDT).

All patients received mechanical bowel preparation (MBP) 1 day before surgery unless contraindicated due to bowel stenosis, in which case, MBP was then replaced by

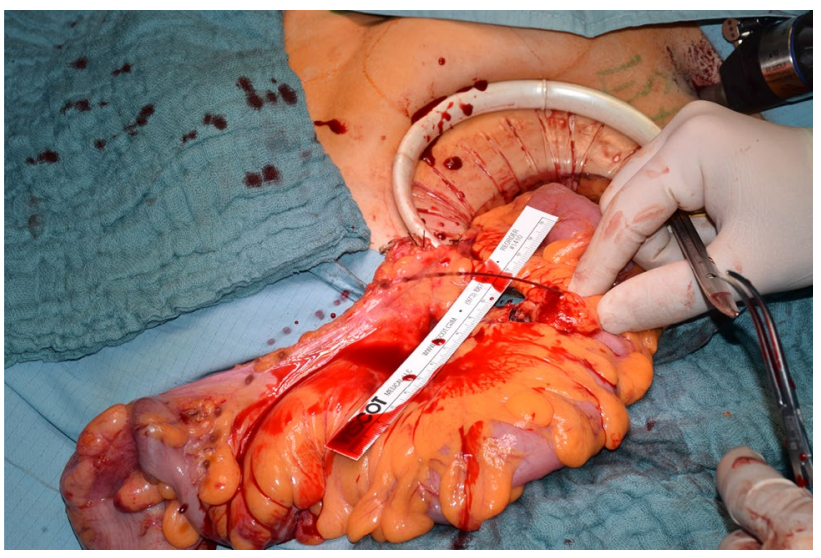

Fig. 1 Cold-steel-test performed by severing the colic marginal artery of Drummond. The pulsatile blood jet is measured in centimeters of length

an enema on operation day. During this study, oral antibiotics were not given 1 day before surgery, since this was still not standard procedure at our department. All patients received a perioperative intravenous single-dose antibiotic prophylaxis and epidural analgesia.

The low anterior resection with total mesorectal excision was done according to the surgical principles defined by Heald et al. and Enker et al. [24, 25]. A high tie technique, defined by division of the IMA at its origin, was performed in all patients. The inferior mesenteric vein was divided below the pancreas and the lesser sac was entered via the medial approach. Dissection in the mesocolic plane was performed until the origin of the middle colic artery was reached and thus allowing for maximal mobilization of the left colon as well as the left-sided transverse colon. Total mesorectal excision und transection of the rectum followed. In a laparoscopic procedure, the specimen was then exteriorized via a small incision in the left middle abdomen allowing for $\mathrm{O}_{2} \mathrm{C}^{\circledR}$ measurement at the level of the left colon as well as the mobilized transverse colon. Once the mesentery was completely divided and the descending colon transected with a linear cutting stapler machine, a CST was performed after securing a systolic blood pressure of at least $120 \mathrm{mmHg}$. The length of the resulting pulsatile blood jet was measured in terms of length in centimeters and video documented (Fig. 1). The blood pressure during the CST was recorded.

A flat glass fiber $\mathrm{O} 2 \mathrm{C}^{\circledR}$ probe (LFX-55), covered with a sterile polyurethane drape and utilizing laser Doppler flowmetry as well as tissue spectrometry, was used to measure three different parameters (Fig. 2): SO2 (capillary venous oxygen saturation), expressed in percent and reflecting the condition of local tissue hypoxia, $\mathrm{rHb}$ (relative hemoglobin amount), expressed in arbitrary units and reflecting venous filling of microvessels, and flow (blood flow velocity), 


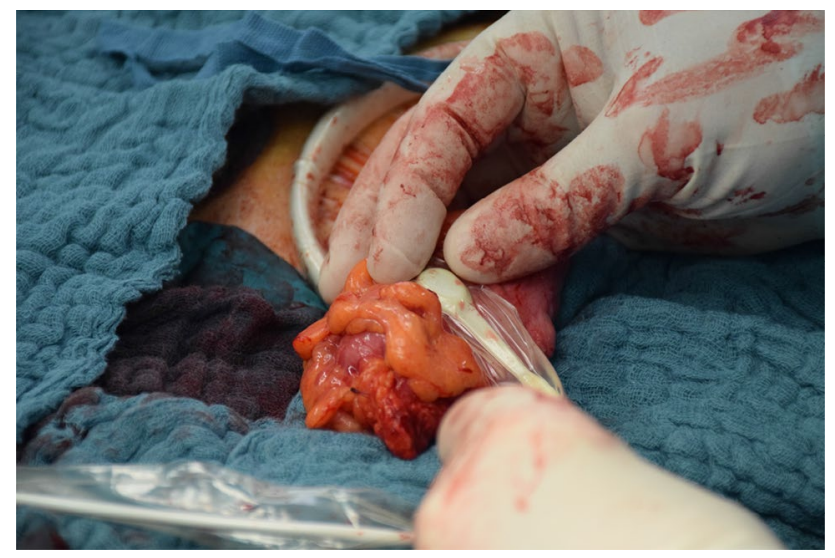

Fig. $2 \mathrm{O} 2 \mathrm{C}$ measurement at the colon stump

also expressed in arbitrary units and reflecting blood flow velocity.

A digital protocol with designated points of measurement on the colonic and rectal stumps was specifically developed for the study and embedded into the machine's software. The measurement was performed under ambient light and after turning off the surgical light. The $\mathrm{O} 2 \mathrm{C}^{\circledR}$ probe was controlled by a footswitch. The surgeon had a live monitor view throughout the course of measurement at each point of probe placement and could decide anytime to cancel or to save the measured values. Once saved, the parameters could not be manipulated or changed.

The $\mathrm{O} 2 \mathrm{C}^{\circledR}$ measurement was then performed according to the aforementioned protocol at four different points on the serosal part of the descending colon stump (M1: mesenteric side, $1 \mathrm{~cm}$ proximal to the staple line, M2: central, $3 \mathrm{~cm}$ proximal to the staple line, M3: antimesenteric, $1 \mathrm{~cm}$ proximal to the staple line, and M4: central and adjacent to the staple line) and at an additional point of reference on the midst of the transverse colon (Figs. 3, 4).

Following transection of the rectum, $\mathrm{O} 2 \mathrm{C}^{\circledR}$ measurement was performed transanally at the rectal stump (M1: dorsal to the staple line and M2: ventral to the staple line) due to better reachability (Fig. 5). If an intersphincteric resection was performed, followed by a hand-sewn coloanal anastomosis, no transanal $\mathrm{O} 2 \mathrm{C}^{\circledR}$ measurement was undertaken, since no rectal mucosa was left. One surgeon performed all $\mathrm{O} 2 \mathrm{C}^{\circledR}$ measurements.

A side-to-end double-stapled anastomosis was used unless a coloanal hand-sewn anastomosis was fashioned, in which case, an end-to-end reconstruction was chosen. A defunctioning ileostomy was fashioned in all patients unless the surgeon decided to refrain from defunctioning at his or her preference.

All patients received a water-soluble contrast enema during follow-up to assess the integrity of the anastomosis. This was done in case of clinical suspicion of an anastomotic leak during inpatient stay or before closure of the ileostomy (6 weeks-6 months after discharge depending on whether the patient was to receive adjuvant therapy or not). Otherwise and in case no ileostomy was fashioned, a contrast enema was done empirically before discharge to satisfy the study objectives. The results of the contrast enemas were recorded. This constituted the closing-up step of data collection per patient. Anastomotic leakage was defined in this study as a symptomatic leakage leading to therapeutic intervention, with or without re-laparotomy, i.e., grade $\mathrm{B}$ and $\mathrm{C}$ according to the classification of the International Study Groups of Rectal Cancer (ISREC) [26, 27]. Sorting out ischemic events leading to anastomotic failure was considered paramount in this study to enable a differentiated statistical evaluation. A grade A anastomotic finding requires no change in patient management and heals spontaneously in this regard [28]. This led to the decision not to list a potential grade A finding under anastomotic failure in the study design.
Fig. 3 Points of probe placement

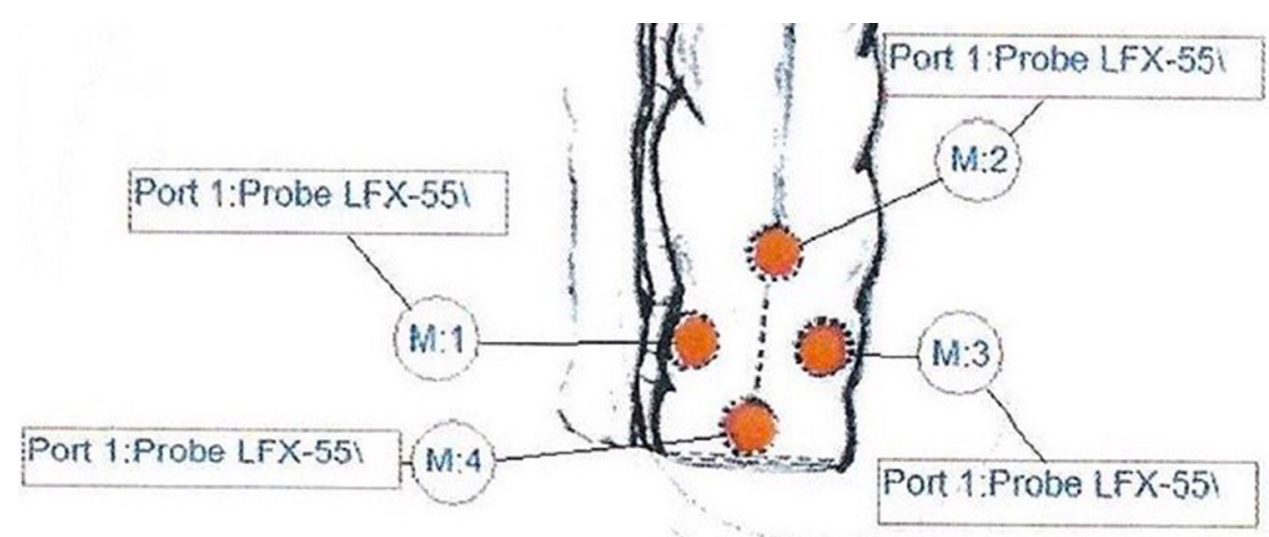




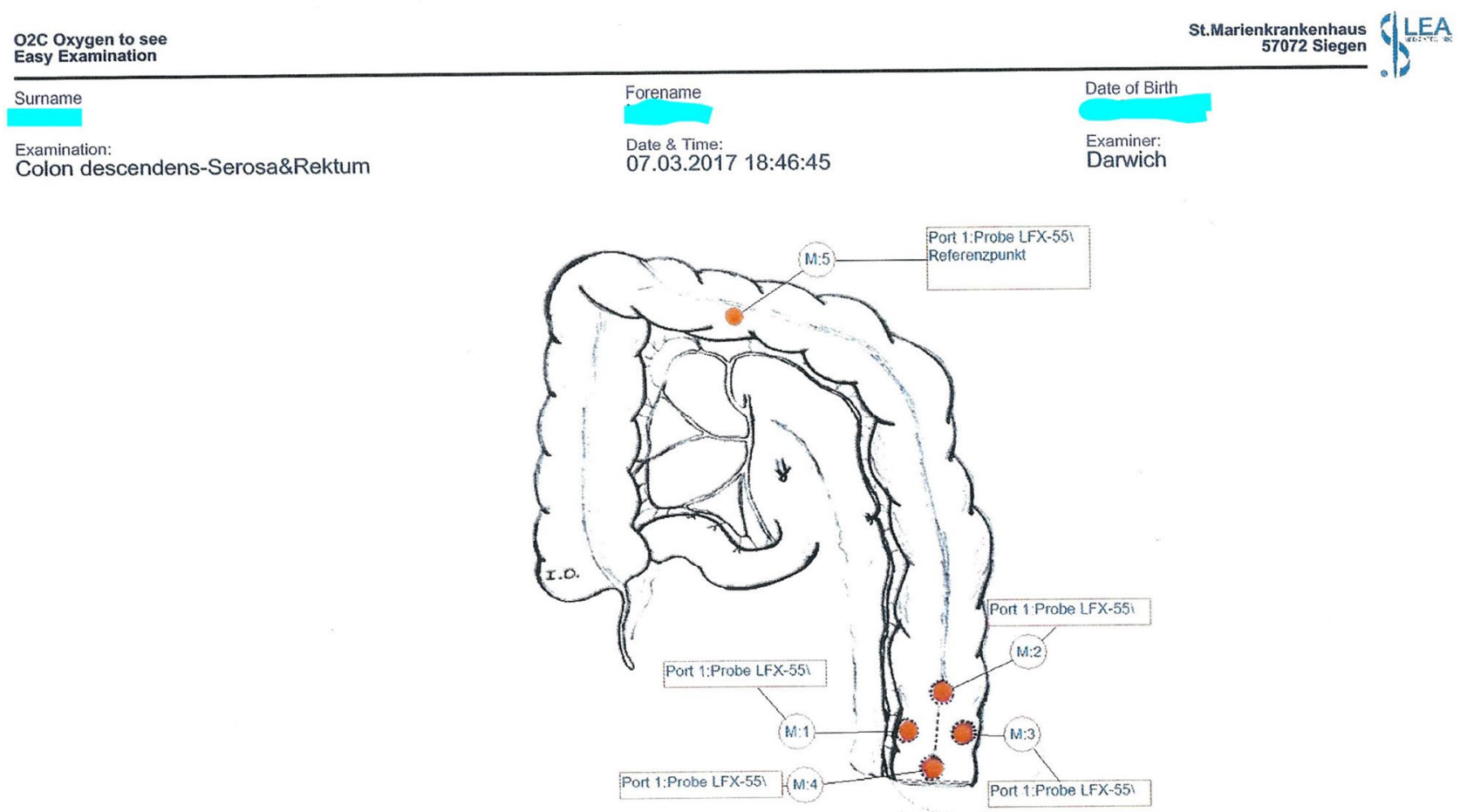

\begin{tabular}{|c|c|c|c|c|c|c|}
\hline & \multicolumn{5}{|c|}{ Session 1: Messung1 } & \multirow[t]{2}{*}{ // Finding >> } \\
\hline S & & & & & & \\
\hline & & & & & 07.03 .18 & - \\
\hline & & First Exammation & 88 & First Examination & 285 & First Examination \\
\hline & 92 & First Examination & 100 & First Examination & 275 & First Examination \\
\hline$M: 3$ & 14 & First Examination & 108 & First Examination & 370 & First Examination \\
\hline M:4 & 91 & First Examination & 101 & First Examination & 185 & First Examinetion \\
\hline$M: 5$ & 90 & First Examination & 85 & First Examination & 364 & First Examination \\
\hline
\end{tabular}

Fig. $4 \mathrm{O} 2 \mathrm{C}^{\circledR}$ measurement protocol showing the designated points of probe placement on the colon serosa. M1: mesenteric, M3: antimesenteric, and M2 and M4: proximal and distal, respectively, to the future site of anastomosis. M5 is reference point measured at the transverse colon

\section{Statistical analysis}

The anastomotic outcome was converted into a binary during statistical analysis ( 0 for AL and I for no AL). The mean of the data collected per patient at the four points of measurement on the colonic stump and the two points of measurement on the rectal stump was calculated for each of the different $\mathrm{O} 2 \mathrm{C}^{\circledR}$ parameters and designated as $\mathrm{Mm}$. Furthermore, the mean and standard deviation of each of the $\mathrm{O} 2 \mathrm{C}^{\circledR}$ parameters was calculated for the patient group that had an anastomotic leak and the patient group with an intact anastomosis. Fisher's exact test, $t$ test, Cochran-Armitage test, and Mann-Whitney $U$ test were used to check for significance of associations. Correlations between $\mathrm{O}_{2} \mathrm{C}^{\circledR}$ measurements and the CST were analyzed using correlation coefficients (Pearson and Spearman) to check for validity. Correlations between $\mathrm{O} 2 \mathrm{C}^{\circledR}$ data and the anastomotic leak were analyzed with logistic regression. Statistical analysis was conducted with SAS.

Feasibility of intraoperative use and correlation of collected $\mathrm{O} 2 \mathrm{C}^{\circledR}$ parameters with the CST constituted the primary endpoint, whereas correlation of the parameters with 


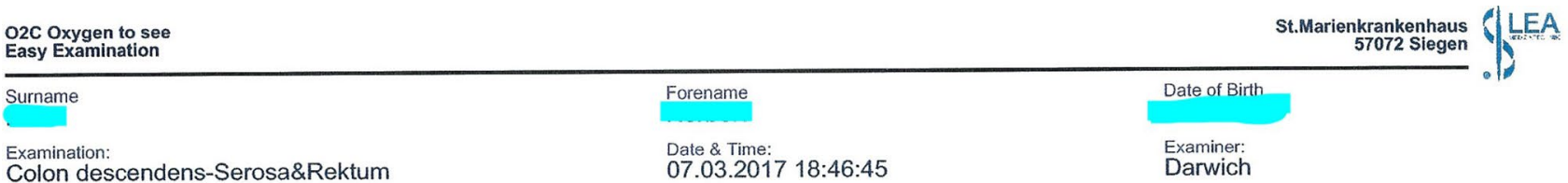

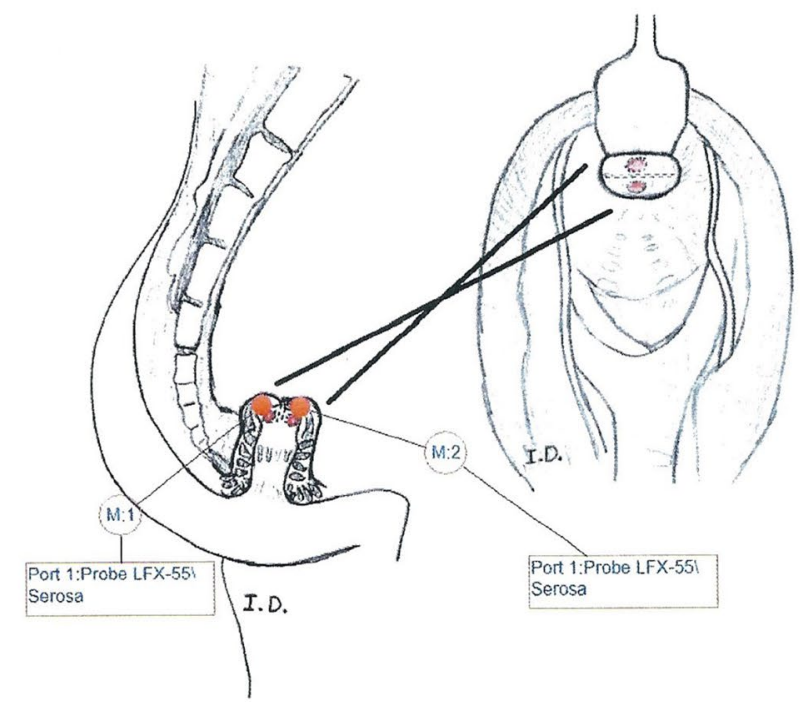

\begin{tabular}{|l|l|l|l|l|}
\hline & Session 2: Messung 2 \\
\hline
\end{tabular}

Statement: Cold-Steel-Test: $5 \mathrm{~mm}$ bei einem RR: 130/60 mmHg, transanale Messung am Rektumstumpf, Karnofsky: $100 \%$. - Darwich,

Fig. $5 \mathrm{O} 2 \mathrm{C}^{\circledR}$ measurement protocol showing the designated points of transanal probe placement on the rectum mucosa. M1 (Rec1): dorsal and M2 (Rec2): ventral

the anastomotic outcome constituted the secondary endpoint of this study.

\section{Results}

Between 2015 and 2017, 40 patients were enrolled in this prospective study $(19 \mathrm{f}, 21 \mathrm{~m}) .61 .8 \%$ of the patients received neoadjuvant therapy. A diverting ileostomy was performed in $85.3 \%$ of the patients who received an anastomosis. A Hartmann procedure had to be done in five of the patients. Three patients did not receive $\mathrm{O} 2 \mathrm{C}^{\circledR}$ measurement because of a broken $\mathrm{O} 2 \mathrm{C}^{\circledR}$ probe. One patient died on the first day after surgery due to a sudden cardiac arrest (confirmed through autopsy). Thirtyone patients (16 f, $15 \mathrm{~m}$ ) were left for statistical analysis (Table 1).

The overall rate of anastomotic leakage was $26 \%$, including the three patients who did not undergo $\mathrm{O} 2 \mathrm{C}^{\circledR}$ measurement due to probe defect, yet received an anastomosis. Nine patients developed a grade B or grade $\mathrm{C}$ anastomotic leakage. Five patients had grade $\mathrm{A}$ anastomotic findings, which healed spontaneously on follow-up, so that uneventful ileostomy closure was performed. 
Table 1 Patient's characteristics

\begin{tabular}{ll}
\hline Variable & Value \\
\hline Mean age (years) & $66.74(37-89)$ \\
Sex (F/M) & $16 / 15$ \\
ASA & I (1), II (18), III (12) \\
KI 70\% (n) & 4 \\
KI 80\% (n) & 2 \\
KI 90\% (n) & 4 \\
KI 100\% (n) & 21 \\
\hline
\end{tabular}

ASA American Society of Anesthesiologists Status, KI Karnofsky index

Intraoperative $\mathrm{O} 2 \mathrm{C}^{\circledR}$ measurement was done in a matter of 3-4 min per patient with no difficulties. In three patients, no measurement was done because of a fractured probe cable, which was then replaced by the manufacturer.

Sex $(p=0.2524)$, age $(p=0.3940)$, neoadjuvant therapy $(p=0.4267)$, performing a defunctioning loop ileostomy
( $p=0.2933$ ) and surgical technique (laparoscopic vs. open, $p=0.3940$ ), were not significant predictors of an increased risk of AL in this study. A reduced Karnofsky index was found on the other hand to significantly increase the risk of $\operatorname{AL}(p=0.0093)$. No statistically significant association was found between the length of the pulsatile blood jet during the CST and anastomotic leak ( $p=0.1195)$.

The intraoperative systolic blood pressure recorded during the CST had no statistically significant effect on the anastomotic outcome $(p=0.7471)$ (Table 2).

Colonic SO2-M3, Flow-M1, Flow-M3, and the mean flow per patient (Flow-Mm) significantly predicted the risk of an AL in this study (Table 3). A weak association was detected in one other parameter collected at the colonic stump (rHb-M2, $p=0.0757)$. Only one parameter collected dorsally on the rectum stump (rHb-Rec1) showed a weak association with the anastomotic outcome in terms of leakage $(p=0.0768)$. Analysis of the remaining $\mathrm{O}_{2} \mathrm{C}^{\circledR}$ parameters did not show a statistically significant association with the anastomotic outcome. The mean values of all
Table 2 Analysis of patient characteristics and other variables with respect to anastomotic leak (31 patients fit for analysis)

\begin{tabular}{|c|c|c|c|c|}
\hline Variable & Intact anastomosis & Anastomotic leak & Test & $p$ \\
\hline \multicolumn{5}{|l|}{ Sex } \\
\hline Male $n(\%)$ & $9(60 \%)$ & $6(40 \%)$ & \multirow{2}{*}{$\begin{array}{l}\text { Fisher's } \\
\text { exact test }\end{array}$} & \multirow[t]{2}{*}{0.2524} \\
\hline Female $n(\%)$ & $13(81 \%)$ & $3(19 \%)$ & & \\
\hline \multicolumn{5}{|l|}{ Mean age } \\
\hline 65 years $(n)$ & 22 & & \multirow[t]{2}{*}{$t$ test } & \multirow[t]{2}{*}{0.3940} \\
\hline 70 years $(n)$ & & 9 & & \\
\hline \multicolumn{5}{|l|}{ Technique } \\
\hline Open $n(\%)$ & $4(57 \%)$ & $3(43 \%)$ & \multirow[t]{2}{*}{ Fisher's exact test } & \multirow[t]{2}{*}{0.3841} \\
\hline Laparoscopic $n(\%)$ & $18(75 \%)$ & $6(25 \%)$ & & \\
\hline \multicolumn{5}{|l|}{ Karnofsky index } \\
\hline $70 \%$ & $0(0 \%)$ & $4(100 \%)$ & \multirow[t]{4}{*}{ Cochran-Armitage trend test } & \multirow[t]{4}{*}{0.0093} \\
\hline $80 \%$ & $2(100 \%)$ & $0(100 \%)$ & & \\
\hline $90 \%$ & $3(75 \%)$ & $1(25 \%)$ & & \\
\hline $100 \%$ & $17(81 \%)$ & $4(19 \%)$ & & \\
\hline \multicolumn{5}{|l|}{ Mean CST blood jet } \\
\hline $10.4 \mathrm{~cm}$ (SD: 15.27) (n) & & 9 & $U$ test & 0.1195 \\
\hline $16.9 \mathrm{~cm}(\mathrm{SD}: 15.42)(n)$ & 22 & & & \\
\hline \multicolumn{5}{|l|}{ Mean systolic BP } \\
\hline $133 \mathrm{mmHg}$ (SD: 15.6) (n) & & 9 & $t$ test & 0.7471 \\
\hline $135 \mathrm{mmHg}$ (SD: 17.4) $(n)$ & 22 & & & \\
\hline \multicolumn{5}{|l|}{ Neoadjuvant therapy } \\
\hline Primary surgery $n(\%)$ & $10(83.3 \%)$ & $2(16.7 \%)$ & Fisher's exact test & 0.4184 \\
\hline nCRT/nRT $n(\%)$ & $12(63.2 \%)$ & $7(36.8 \%)$ & & \\
\hline \multicolumn{5}{|l|}{ Defunctioning ileostomy } \\
\hline Without ileostomy $(n)$ & $4(100 \%)$ & $0(0 \%)$ & Fisher's exact test & 0.2952 \\
\hline $\begin{array}{l}\text { With } \\
\text { ileostomy }(n)\end{array}$ & $18(66.7 \%)$ & $9(33.3 \%)$ & & \\
\hline
\end{tabular}

$C S T$ cold steel test, $B P$ blood pressure, $n$ number of patients, $S D$ standard deviation 
Table 3 O2 $\mathrm{C}^{\circledR}$ parameters significantly associated with anastomotic outcome

\begin{tabular}{|c|c|c|c|c|}
\hline Variable & $\begin{array}{l}\text { Intact } \\
\text { anastomo- } \\
\text { sis }\end{array}$ & $\begin{array}{l}\text { Anas- } \\
\text { tomotic } \\
\text { leak }\end{array}$ & Test & $p$ \\
\hline \multicolumn{5}{|l|}{ Mean SO2-M3 } \\
\hline $88 \%(\mathrm{SD} 17.5)(\mathrm{n})$ & 22 & & $U$ test & 0.0404 \\
\hline $73 \%(\mathrm{SD} 26.0)(n)$ & & 9 & & \\
\hline \multicolumn{5}{|l|}{ Mean Flow-M1 } \\
\hline $248 \mathrm{AU}(\mathrm{SD} 109.9)(n)$ & 22 & & $U$ test & 0.0250 \\
\hline $163 \mathrm{AU}(\mathrm{SD} 114.4)(n)$ & & 9 & & \\
\hline \multicolumn{5}{|l|}{ Mean Flow-M3 } \\
\hline 218 AU (SD 81.3) $(n)$ & 22 & & $U$ test & 0.0057 \\
\hline 130 AU (SD 67.6) (n) & & 9 & & \\
\hline \multicolumn{5}{|l|}{ Mean Flow-Mm } \\
\hline $217 \mathrm{AU}(\mathrm{SD} 55.0)(n)$ & 22 & & $U$ test & $\mathbf{0 . 0 1 7 7}$ \\
\hline $162 \mathrm{AU}(\mathrm{SD} 91.6)(n)$ & & 9 & & \\
\hline
\end{tabular}

$A U$ arbitrary units, $n$ number of patients, $S D$ standard deviation

$\mathrm{O} 2 \mathrm{C}^{\circledR}$ parameters collected at the reference point (M5) did not significantly differ between the groups, with and without anastomotic leakage.

The above variables that showed a statistically significant as well as a weak association with the anastomotic outcome were then analyzed with logistic regression. This yielded three parameters with varying significance. Flow-M3 was significant $(p=0.0348)$ with an area under the curve (AUC) of 0.881. Flow-Mm and Flow-M1 showed a weak association $(p=0.0604$, AUC: 0.778 and $p=0.0752$, AUC: 0.763 , respectively).

Statistical analysis looking for associations between the variables (Age, Sex, Karnofsky index, surgical technique, systolic blood pressure, and $\mathrm{O}_{2} \mathrm{C}^{\circledR}$ parameters) and the length of the pulsatile blood jet during the CST showed a few significant correlations. Sex correlated significantly with the CST $(p=0.0160)$. Furthermore, significant reversed correlations were detected between the CST and rHb-M2 $(p=0.0064, r:-0.4787), \mathrm{rHb}-\mathrm{Mm}(p=0.0138, r:-0.4379)$, rHb-M4 ( $p=0.0488, r:-0.3568)$, and rHb-M3 ( $p=0.0603$, $r=-0.3412)^{1}$

Logistic regression analysis was then used to identify cut-off values for the three flow parameters that predicted a risk of AL. The cut-off values are listed in Table 4 with the sensitivity and specificity for each value. The sensitivity displays the odds of correctly predicting an AL. The specificity displays the odds of correctly foretelling an uneventful anastomotic outcome.

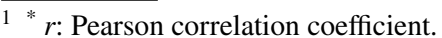

Table 4 Cut-off values for $\mathrm{O} 2 \mathrm{C}^{\circledR}$ parameters

\begin{tabular}{llllll}
\hline Variable & $\begin{array}{l}\text { Cut-off } \\
\text { (AU) }\end{array}$ & $\begin{array}{l}\text { Sensitiv- } \\
\text { ity } \%\end{array}$ & $\begin{array}{l}\text { Specific- } \\
\text { ity } \%\end{array}$ & AUC $p$ \\
\hline Flow_M1 & 208.02 & 88.89 & 72.72 & 0.763 & 0.0752 \\
Flow_Mm & 180.04 & 88.89 & 68.18 & 0.778 & 0.0604 \\
Flow_M3 & 164.43 & 88.89 & 63.64 & $\mathbf{0 . 8 2 3}$ & $\mathbf{0 . 0 2 6 8}$ \\
\hline
\end{tabular}

$A U$ arbitrary units, $A U C$ area under the curve

\section{Discussion}

AL remains one of the most dreaded complications to be dealt with after a low anterior resection. A reliable device for quantitative measurement of tissue perfusion that could predict anastomotic healing after a low anterior resection is still lacking.

This prospective study addresses a device called $\mathrm{O} 2 \mathrm{C}^{\circledR}$ that utilizes noninvasive laser Doppler flowmetry and tissue spectrometry for the quantitative assessment of bowel perfusion. This device had previously found colorectal uses in clinical trials, yet only under the eminence based assumption that it is effective in assessing bowel perfusion and thus adequate for investigating other study goals [22, 23].

We looked in this study at three main aspects of this device: feasibility and practicability of the device for intraoperative use, validity of the collected data, and correlation of the collected data with anastomotic leak.

\section{Feasibility and practicability}

The intraoperative use of $\mathrm{O} 2 \mathrm{C}^{\circledR}$ proved to be easy and feasible with a minimal time cost of 3-4 min per measurement. Yet, the measuring probe of the device was shown to be sensitive to frequent handling, which resulted in a fractured probe cable and failed measurement in three of the patients recruited for the study.

\section{Validity of the collected data}

In an effort to validate this method of perfusion assessment of the bowel, we analyzed it in comparison to the only other method of assessment available at the time for this purpose, namely the CST. In a prospective study by Novell et al. (Br J Surg 1990; 77: 137-8), it was shown that fashioning an anastomosis despite an absent pulsatile blood flow after transecting the marginal artery at the stump of the left colon significantly increased the rate of anastomotic leak. In an effort to try to utilize the CST as a reference method of validation in our study, we analyzed the association of the length of the pulsatile blood jet in centimeters with the anastomotic outcome. For obvious reasons, anastomoses in this study were fashioned only if pulsatile blood flow out of 
the marginal colonic artery was confirmed. Furthermore, the association between the CST and different variables, including the measured parameters, was statistically analyzed with the help of correlation coefficients.

While significant reversed correlations were found between the CST and some $\mathrm{rHb}$ values measured with the $\mathrm{O} 2 \mathrm{C}^{\circledR}$ device, no statistically significant association was found between the length in centimeters of the pulsatile blood jet during the CST and anastomotic leak $(p=0.1195)$ despite a quite interesting observed tendency towards a difference between the groups $(10.4 \mathrm{~cm}$ in the AL group vs. $16.9 \mathrm{~cm}$ in the group with intact anastomoses). This result challenges of course the rationale of validating the $\mathrm{O}_{2} \mathrm{C}^{\circledR}$ measurements with the CST in this study. Yet, one has to emphasize that the CST was analyzed here in terms of the length of the pulsatile blood jet and not in terms of the absence or presence of pulsatile blood flow in its correlation to anastomotic leak. Thus, it can be suggested that a higher number of cases would have been necessary to achieve statistical significance. A larger study ought to elaborate more on these observations.

\section{Prediction of anastomotic outcome}

An AL rate of $26 \%$ in this study was a major concern for the surgeon and a heavy burden for the patients. Yet, this may have enabled a more differentiated statistical evaluation of the $\mathrm{O}_{2} \mathrm{C}^{\circledR}$ data collected. The causes behind this leak rate may have been diverse. All four patients who had a KI of $70 \%$ had an AL. This was also evident in the significant association between the $\mathrm{KI}$ and $\mathrm{AL}(p=0.0093)$. It is also worthy to mention that at the time, data for this study were collected, administering oral antibiotics 1 day prior to surgery was not standard procedure at our department [29]. Since then, oral antibiotics were added to our regimen of MBP 1 day prior to rectal surgery and we have witnessed a drastic reduction in our AL rate [30].

We found significant associations between $\mathrm{O} 2 \mathrm{C}^{\circledR}$ parameters and the anastomotic outcome. The dominating parameter in this respect was the flow parameter, Flow-M3, collected at the antimesenteric side of the descending colon stump (Fig. 5), which predicted AL with high statistical significance $(p=0.0057)$. The lower the value of this parameter, measured before completion of the anastomosis, the higher was the chance of an anastomotic leak. Similar significant associations, although to a lesser extent, were found at Flow$\mathrm{Mm}$, Flow-M1, and SO2-M3 with $p=0.0177, p=0.0250$, and $p=0.0404$, respectively. It was quite surprising to see that data collected at the rectal stump did not associate significantly with anastomotic leakage (with the exception of a weak rHb-Rec1 association collected dorsally and which could not be confirmed by logistic regression analysis). Previous evidence in literature suggested a role of reduced perfusion in the rectal stump in increasing the rate of anastomotic leak [31, 32]. Limited statistical power might have been the reason for not being able to detect an association in our study in this regard.

All the $\mathrm{O}_{2} \mathrm{C}^{\circledR}$ parameters (Flow, $\mathrm{SO} 2$ and $\mathrm{rHb}$ ), collected at the reference point in the middle of the transverse colon M5 (Fig. 1), did not significantly influence the anastomotic outcome in this study. Bearing in mind that the superior mesenteric artery provides the main blood supply of the transverse colon via the middle colic artery, no associations between the anastomotic outcome and the $\mathrm{O} 2 \mathrm{C}^{\circledR}$ parameters, collected at the reference point M5, had been expected. This observation supports the presumption that the measuring process was done evenly and similarly in all patients and that the detected significant associations at the level of the colonic stump were not the result of a handling or user error.

\section{$02 C^{\circledR}$ cut-off values}

Logistic regression analysis yielded three parameters with varying significance: Flow-M3 $(p=0.0348$, AUC: $0.881)$, Flow-Mm ( $p=0.0604$, AUC: 0.778$)$, and Flow-M1 $(p=0.0752$, AUC: 0.763$)$. Also with the help of logistic regression, cut-off values for the above parameters with the highest respective sensitivity and specificity were determined. The $\mathrm{O}_{2} \mathrm{C}^{\circledR}$ parameter with the highest predicting accuracy of anastomotic outcome was found to be Flow-M3 with a cut-off value of $164.43 \mathrm{AU}$, a sensitivity of $88.89 \%$, and a specificity of $63.64 \%$ ( $p=0.0268$, AUC: 0.823$)$. This means that an anastomotic leak is in $88.89 \%$ of the cases likely to be correctly predicted if the Flow-M3 values measured were lower than 164.43 AU.

\section{Association of $02 \mathrm{C}^{\circledast}$ parameters with risk factors of al}

Gender, age, neoadjuvant therapy, performing a defunctioning loop ileostomy, and surgical technique were not found to significantly influence the anastomotic outcome in this study. Although a tendency towards more anastomotic leaks in male patients could be observed, it did not reach statistical significance, however. Limited statistical power might have also been an issue here.

A reduced Karnofsky index was found to significantly increase the risk of developing an AL. This parallels data in the literature that associates a high ASA score (American Society of Anaesthesiologists Risk Score) with a higher risk of anastomotic failure [33].

\section{Comparing $02 \mathrm{C}^{\circledR}$ with fluorescence angiography}

It is quite noteworthy to state that within the time during which data were collected for this study, several publications 
appeared describing the use of fluorescence angiography via intravenous injection of indocyanine green (ICG) to assess bowel perfusion [33-36]. Despite the impressive imagery provided by this method showing demarcated green fluorescent perfused regions of the bowel, there is still place here in our opinion for subjectivity of judgment when it comes to surgical decision-making. This is especially evident when the level of fluorescence, observed by the surgeon, is graded as absent, sufficient, and optimal, as described in one of the published papers [35]. This comes in contrast to $\mathrm{O}_{2} \mathrm{C}^{\circledR}$ which attempts to define objective quantitative measurements in identifying adequate bowel perfusion.

The invasive nature of fluorescence angiography on the other hand, which involves the intravenous administration of ICG, regardless of how low the complication rate is, must also be taken into consideration [37].

Last but not least, cost effectiveness plays a major role during decision-making each time which a healthcare provider considers acquiring new medical technologies. The acquisition costs of the $\mathrm{O} 2 \mathrm{C}^{\circledR}$ device at our department amounted to about $€ 25000$. This comes in contrast to costs of about $€ 110000$ to acquire near-infrared fluorescence imaging technology [36]. Furthermore, a single-use sterile polyurethane drape, used to cover the glass fiber $\mathrm{O}_{2} \mathrm{C}^{\circledR}$ probe during intraoperative measurement, costs $€ 6$, whereas ICG costs about $€ 50$ per 25-mg vial [36].

Obviously, comparative studies between the two mentioned techniques are needed to clarify the above raised questions.

\section{Limitations of this study and future implications}

This study has a number of limitations. First, the relatively small number of patients may have resulted in limited statistical power. Second, the prospective, non-randomized, and observatory nature of this cohort study prevented change of surgical strategy in accordance with the collected measurements. The level of transection of the proximal colon was thus based only on the pulsatile flow of the severed marginal artery. Furthermore, the non-randomized structure of this study may have allowed for bias in terms of surgical decision-making as can been seen with the surgeon's preference not to divert with a loop ileostomy in some patients. Third, a reliable method of testing adequate bowel perfusion other than the "cold-steel-test" to validate the collected $\mathrm{O} 2 \mathrm{C}^{\circledR}$ data was not available at the start of this study. This paves the way, however, for a study comparing fluorescence angiography with $\mathrm{O} 2 \mathrm{C}^{\circledR}$.

At our surgical department, a further prospective study analyzing $\mathrm{O} 2 \mathrm{C}^{\circledR}$ measurements prior to performing lower limb amputations is already underway. Furthermore, a comparative randomized study between $\mathrm{O}_{2} \mathrm{C}^{\circledR}$ and fluorescence angiography while utilizing the above-mentioned cut-off values is currently being considered.

\section{Conclusion}

Intraoperative $\mathrm{O} 2 \mathrm{C}^{\circledR}$ assessment of bowel blood supply is feasible and could be an important tool of a quantitative and noninvasive measurement. The parameters suggested by this study to predict anastomotic leakage could set the basis for further trials in trying to check for their validity. Clearly, high-powered randomized trials are needed.

Acknowledgements Statistical analysis was performed by Prof. Dr.sc. hum. habil. Christel Weiss, Head of the Institute for Medical Statistics at the University Hospital in Mannheim, Germany.

\section{Compliance with ethical standards}

Conflict of interest The authors have no source of funding and no conflict of interest to declare.

Ethical approval The study was approved by the ethics committee of the Mannheim Medical University (2015-410 M-MA-§23b MPG).

Informed consent Informed consent was obtained from each included patient.

Research involving human participants and/or animals The study did not involve animals.

Open Access This article is distributed under the terms of the Creative Commons Attribution 4.0 International License (http://creativeco mmons.org/licenses/by/4.0/), which permits unrestricted use, distribution, and reproduction in any medium, provided you give appropriate credit to the original author(s) and the source, provide a link to the Creative Commons license, and indicate if changes were made.

\section{References}

1. Caulfield H, Hyman NH (2013) Anastomotic leak after low anterior resection: a spectrum of clinical entities. JAMA Surg 148:177-182

2. Branagan G, Finnis D (2005) Prognosis after anastomotic leakage in colorectal surgery. Dis Colon Rectum 48:1021-1026

3. Murrell ZA, Stamos MJ (2006) Reoperation for anastomotic failure. Clin Colon Rectal Surg 19:213-216

4. Matthiessen $P$, Haapamäki MM, Boström P, Rutegård J, Rutegård M (2018) Population-based cohort study of the impact on postoperative mortality of anastomotic leakage after anterior resection for rectal cancer. BJS Open 93:498-503

5. Matthiessen P, Hallböök O, Andersson M, Rutegård J, Sjödahl R (2004) Risk factors for anastomotic leakage after anterior resection of the rectum. Colorectal Dis 6:462-469

6. Bertelsen CA, Andreasen AH, Jørgensen T, Harling H (2010) Anastomotic leakage after anterior resection for rectal cancer: risk factors. Colorectal Dis 12:37-43 
7. Matthiessen P, Hallböök O, Rutegård J, Simert G, Sjödahl R (2007) Defunctioning stoma reduces symptomatic anastomotic leakage after low anterior resection of the rectum for cancer: a randomized multicenter trial. Ann Surg 246:207

8. Hida JI, Okuno K (2013) High ligation of the inferior mesenteric artery in rectal cancer surgery. Surg Today 43:8-19

9. Bonnet $\mathrm{S}$ et al (2012) High tie versus low tie vascular ligation of the inferior mesenteric artery in colorectal cancer surgery: impact on the gain in colon length and implications on the feasibility of anastomoses. Dis Colon Rectum 55:515-521

10. Rutegard M (2012) Author's reply: high tie in anterior resection for rectal cancer confers no increased risk of anastomotic leakage (Br J Surg 2012; 99: 127-132). Br J Surg 99:127-132

11. Bruch HP, Schwandner O, Schiedeck THK, Roblick UJ (1999) Actual standards and controversies on operative technique and lymph-node dissection in colorectal cancer. Langenbeck's Arch Surg 384:167-175

12. Yang Y, Wang G, He J, Zhang J, Xi J, Wang F (2018) High tie versus low tie of the inferior mesenteric artery in colorectal cancer: a meta-analysis. Int J Surg 52:20-24

13. Fujii $\mathrm{S}$ et al (2018) Randomized clinical trial of high versus low inferior mesenteric artery ligation during anterior resection for rectal cancer. BJS Open 2:195-202

14. Karliczek A, Harlaar NJ, Zeebregts CJ, Wiggers T, Baas PC, van Dam GM (2009) Surgeons lack predictive accuracy for anastomotic leakage in gastrointestinal surgery. Int J Colorectal Dis 24:569-576

15. Horisberger K, Kienle P (2013) Rektumkarzinom-Teil 2: operationstechnik. Allgemein-und Viszeralchirurgie up2date 8:287-295

16. Novell JR, Lewis AAM (1990) Peroperative observation of marginal artery bleeding: a predictor of anastomotic leakage. $\mathrm{Br} \mathrm{J}$ Surg 77:137-138

17. Grace R (1990) Peroperative observation of marginal artery bleeding; a predictor of anastomotic leakage. Br J Surg 77:714

18. Wunder C, Brock RW, Krug A, Roewer N, Eichelbrönner O (2005) A remission spectroscopy system for in vivo monitoring of hemoglobin oxygen saturation in murine hepatic sinusoids, in early systemic inflammation. Comp Hepatol 4:1

19. Walter B, Bauer R, Krug A, Derfuss T, Traichel F, Sommer N (2002) Simultaneous measurement of local cortical blood flow and tissue oxygen saturation by near infra-red laser doppler flowmetry and remission spectroscopy in the pig brain. Springer, Vienna

20. Abel G, Allen J, Drinnan M (2014) A pilot study of a new spectrophotometry device to measure tissue oxygen saturation. Physiol Meas 35:1769

21. Forst T, Hohberg C, Tarakci E, Forst S, Kanna P, Pfützner A (2008) Reliability of lightguide spectrophotometry $\left(\mathrm{O}_{2} \mathrm{C}^{\circledR}\right)$ for the investigation of skin tissue microvascular blood flow and tissue oxygen supply in diabetic and nondiabetic subjects. J Diabetes Sci Technol 2:1151-1156

22. Boyle NH, Manifold D, Jordan MH, Mason RC (2000) Intraoperative assessment of colonic perfusion using scanning laser doppler flowmetry during colonic resection. J Am Coll Surg 191:504-510

23. Komen $\mathrm{N}$ et al (2011) Erratum: high tie versus low tie in rectal surgery: comparison of anastomotic perfusion. Int J Colorectal Dis. https://doi.org/10.1007/s00384-011-1188-6
24. Heald RJ, Ryall RDH (1986) Recurence and survival after total mesorectal excision for rectal cancer. Lancet 133:894

25. Enker WE, Thaler HT, Cranor ML, Polyak T (1995) Total mesorectal excision in the operative treatment of carcinoma of the rectum. J Am Coll Surg 181:335

26. Rahbari NN et al (2010) Definition and grading of anastomotic leakage following anterior resection of the rectum: a proposal by the International Study Group of Rectal Cancer. Surgery 147:339-351

27. Frouws MA et al (2017) "Clinical relevance of a grading system for anastomotic leakage after low anterior resection: analysis from a national cohort database. Dis Colon Rectum 60:706

28. Kulu Y et al (2013) Validation of the International Study Group of Rectal Cancer definition and severity grading of anastomotic leakage. Surg (United States) 153(6):753-761

29. McSorley ST, Steele CW, McMahon AJ (2018) Meta-analysis of oral antibiotics, in combination with preoperative intravenous antibiotics and mechanical bowel preparation the day before surgery, compared with intravenous antibiotics and mechanical bowel preparation alone to reduce surgical-site infec. BJS open 2(4):185-194

30. Gaines S, Shao C, Hyman N, Alverdy JC (2018) Gut microbiome influences on anastomotic leak and recurrence rates following colorectal cancer surgery. Br J Surg 105:e131

31. Vignali A, Gianotti L, Braga M, Radaelli G, Malvezzi L, Di Carlo V (2000) Altered microperfusion at the rectal stump is predictive for rectal anastomotic leak. Dis Colon Rectum 43:76-82

32. Rutegård M, Hassmén $\mathrm{N}$, Hemmingsson $\mathrm{O}$, Haapamäki MM, Matthiessen P, Rutegård J (2016) Anterior resection for rectal cancer and visceral blood flow: an explorative study. Scand J Surg 105:78

33. Bakker IS, Grossmann I, Henneman D, Havenga K, Wiggers T (2014) Risk factors for anastomotic leakage and leak-related mortality after colonic cancer surgery in a nationwide audit. Br J Surg 101:424-432

34. James DRC et al (2015) Fluorescence angiography in laparoscopic low rectal and anorectal anastomoses with pinpoint perfusion imaging- a critical appraisal with specific focus on leak risk reduction. Color Dis 15:91

35. Gröne J, Koch D, Kreis ME (2015) Impact of intraoperative microperfusion assessment with pinpoint perfusion imaging on surgical management of laparoscopic low rectal and anorectal anastomoses. Colorectal Dis 17:22-28

36. Ris F et al (2018) Multicentre phase II trial of near-infrared imaging in elective colorectal surgery. Br J Surg 105:1359

37. Chu W, Chennamsetty A, Toroussian R, Lau C (2017) Anaphylactic shock after intravenous administration of indocyanine green during robotic partial nephrectomy. Urol Case Rep 12:37-38

Publisher's Note Springer Nature remains neutral with regard to jurisdictional claims in published maps and institutional affiliations. 